\title{
2-D Electrical Resistivity Imaging for Detecting Landslide Vulnerability of Some Tin Mine Sites in Jos South, Plateau State, North Central, Nigeria
}

\author{
Akanbi E. S. ${ }^{1}$, Bulus J.A. ${ }^{2}$ \\ ${ }^{I}$ (Department of Physics, Faculty of Natural Science/ University of Jos, Nigeria) \\ ${ }^{2}$ (Department of Geology, Faculty of Natural Sciencel University of Jos, Nigeria)
}

\begin{abstract}
A possible cause of landslide is mining activity, with the problem exacerbated in areas where mining activities are uncontrolled and unregulated like the Jos-South, North-Central Nigeria. The aim of this study is to use 2-D electrical resistivity imaging as a preliminary tool to investigate landslide vulnerability of some tin mine sites in this area. The Wenner-Schlumberger configuration was used and the apparent resistivity (observed data) was iteratively subjected to inversion process using RES2DINV software, to generate the 2-D resistivity sections. The 2-D Electrical Resistivity models revealed resistivity sections with resistivity generally increasing with depth, that is overburden resistivity < granitic weathered basement resistivity < granitic basement. The exception was that of the model for Gyerro 2 (Sabongida Kanar 2), which revealed a section with overburden resistivity > granitic weathered < granitic basement resistivity.The fluid flow mechanism and weathered zone as indicated by the low resistivity values show the presence of a weak zone within the subsurface of Gyerro 2 where landslides can form. Hence, the subsurface of Gyerro 2 area is vulnerable to land sliding with a weak zone of very low resistivity (4.58 $\Omega-36.4 \Omega$ ) greater than $3600 \mathrm{~m}^{2}$. This weak zone may comprise of high content of clayey material, cassiterite bearing alluvium and water.
\end{abstract}

Keywords: 2-D Electrical Resistivity, granitic, Gyerro 2, Landslide, Weak zone

\section{Introduction}

The term "landslide" describes a wide variety of processes that result in the downward and outward movement of slope-forming materials including rock, soil, artificial fill, or a combination of these. The materials may move by falling, toppling, sliding, spreading, or flowing. Although landslides are primarily associated with mountainous regions, they can also occur in areas of generally low relief. In low-relief areas, landslides occur as cut-and fill failures (roadway and building excavations), river bluff failures, lateral spreading landslides, collapse of mine-waste piles, and a wide variety of slope failures associated with quarries and open-pit mines [1].

Several landslides have occurred in Nigeria but few are recorded except when people are killed and/or a good number of properties are destroyed. Literature on landslides in Nigeria is limited to short reports from the Nigeria Geological Survey Agency (NGSA), Ministry of Environment, the internet and eyewitness reports that mention the disaster and casualty figures [2]. According to [3], no thorough investigation regarding the triggering mechanism and extent and nature of the landslides is usually carried out. Description of the various possible causes of the landslides and nature of the rocks types and weathered materials affected are also not always reported. Most of the occurrences may not have been reported due to negligence and lack of appreciation of this phenomenon at both States and Federal levels. Landslides have occurred over time in some parts of Nigeria destroying lives and properties such as in Osun, Benue, Enugu, Abia, Anambra, Ebonyi and Imo states due to wide spread impact of gully erosion resulting from annual rainfall and subsequent flooding [2]. According to [4] landslides occurred on the Ogbajala hills of Benue State on 3rd September 1987 after days of consecutive rainfall and subsequent flooding. Field measurement of the landslides showed that the slip originated on the upper one third of the hill at depth of $1.37 \mathrm{~m}$ and extended uniformly to about $50 \mathrm{~m}$ down slope before turning into a flow.

Also, according to [3], a swarm of 14 landslides occurred spontaneously within the Azenge Mountain on November $13^{\text {th }}$, 2010 between the hours of 1 and 6 am after torrential rains. According to the authors, $1,123,918 \mathrm{~m}^{3}$ of rock and debris were moved along the sliding surface for more than $1.5 \mathrm{~km}$ to the toe of the mountain within a very few minutes. The authors recommended that human activities along the toe of the hills be reduced and settlements should be sited far away from the hills to avoid further loss of lives in future.

Landslide can also be caused by mining activities. This problem is exacerbated in areas where mining activities are uncontrolled and unregulated, a particular problem in many less developed countries. In the Jos-South Local Government Area (L.G.A) of Plateau state, Younger Granite rocks, which form a distinctive group of intrusive and volcanic rocks bounded by ring dykes or fault, abound. Volcanic activities which occurred several years 
ago, created vast basaltic plateau and volcanoes, producing regions of mainly narrow and deep valleys, and sediment from the middle of rounded hills with shear facies. The Younger Granite Complex in Jos-South L.G.A area is the Jos-Bukuru complex. Rocks within this Complex include Rayfield Gona Biotite Granite, Bukuru Biotite Granite, Ngell Biotite Granite and Jos Biotite Granite. In addition, rocks of the Crystalline Basement Complex such as Migmatite; and Basaltic rocks such as Newer Basalt are also present.

The phases of volcanic activities involved in the formation of Plateau state, have made it one of the mineral rich states in Nigeria. It is very rich in cassiterite. The Cassiterite deposits in the biotite granites were eroded from the host rocks and deposited in the old river channels. Apart from cassiterite which is the major mineral found in the area, other associated minerals such as columbite, monazite and accessories like zircon and topaz are also found. As a result of the presence of these minerals, a lot of mining activities (formal and informal) have been carried out over the years in the area. The extent of devastated arable land by open cast tin mining is about $316 \mathrm{~km}^{2}$, which comprises of mine spoils, pits, paddocks, site of abandoned equipment mining scars, tailings, mine dumps and ponds, especially along the river valleys [5]. [6] pointed out that the Jos plateau mining region covers an area of approximately $3,670 \mathrm{~km}^{2}$, about $43 \%$ of the total land area of Jos plateau. Jos South local government area is an extensively mined area, which was carried out by the use of heavy earthmoving equipment and draglines. As a result, the zone is characterized by deep excavations and dumping of high overburden, mine ponds, mine tailings and slurry wash deposits (Plate 1).

Several tin mines exist in Jos south local government area. At Sabon Gida Kanar now called Gyerro, and Kassa mines, the cassiterite-rich alluvium occurs under very thick overburden, greater that $15 \mathrm{~m}$ thick in many locations [7]. According to the authors, this alluvium directly overlies the Basement Complex and is overlain by clay. Its thickness is highly variable, from $>20 \mathrm{~cm}$ to as much as $1 \mathrm{~m}$, and this is probably dependent on the configuration of the basement surface. As a result of the thickness of the overburden at Sabon Gida Kanar tin mine and its nature, the method of reaching the mineralised zone is by open cast mining i.e. mechanical stripping of the overburden using draglines. This mine has a peculiar problem of slope failure (sliding) of the overburden which occurs mostly in the raining season, suggesting that water contributes and/or facilitate the sliding [7]. Water probably makes the clay soft and slippery. Subsequent increase in hydrostatic pressure would then trigger the slide. The fact that other mines do not have this problem indicate that the overburden at Sabon Gida Kanar has a peculiar structure. According to [7], at present the sliding is only localised at the paddocks, but there is urgent need to understand the problem and ensure that the sliding does not affect a wide area in future. The obvious impact of mining on Sabon Gida Kanar area is the ability to cause landslides [7]. The large number of mine dumps scattered around the area make the topography rugged and the area difficult and expensive to develop, there is also a large mine lake in the vicinity of the mine.

Geophysical techniques have led to significant results and provided useful information concerning both the landslide geometry reconstruction and the site hydrological characterization. Among these the geo-electrical (electrical resistivity imaging, self-potential, induced polarization) and seismic methods play the most important role. The electrical resistivity method is one of the most used geophysical methods in shallow investigation [8]. It is based on measuring the electrical potentials between one electrode pair while transmitting a direct current between another electrode pair. The technique can be used in three ways: 1) vertical electrical sounding (VES) where electrodes are moved from a mid-point; 2) profiling where the array is moved along a direction with constant electrode spacing, and; 3) Electrical Resistivity imaging where a large number of electrodes and combinations of electrode pairs are used. Electrical resistivity is a parameter exhibiting a large range of values [8] sensitive to various factors like the nature of material (particularly clay percentage), the water content and its conductivity, as well as the rock weathering and fracturing. This explains why this method has been the most applied for landslide investigation purposes [9]. In particular, the Electrical Resistivity Imaging has been largely applied in order to investigate landslide areas [10 and 11]. This technique provides useful data to be used during the pre-event and post-event phases, thanks to its capability of giving information both on the lithostratigraphic sequences and the geometry of the landslide body (lateral extension and thickness), identifying the sliding surfaces between the slide material and the underlying bedrock, and individuating high water content areas.

Jos south local government area is located within the Naraguta area sheet 168 with latitudes $9^{\circ} 30^{\prime}$ to $10^{\circ} 00^{\prime} \mathrm{N}$ and longitude $8^{\circ} 30^{\prime} \mathrm{E}$ to $9^{\circ} 00^{\prime} \mathrm{E}$. It is situated at the North Western part of the Plateau state with its headquarters at Bukuru, which is about $15 \mathrm{~km}$ from the state capital, Jos. The local government area has four districts: Du, Gyel, Kuru and Vwang districts. The towns include Kwata, Kwang, Shen, Dano Garma, Sabon Gida, Chongopyeng, Bar Gada, Barikin-Maiadiko, Doi and Rayfield. Fig. 1 shows the digitised Topography map of the study area.

The aim of this study is to use 2-D electrical resistivity imaging as a preliminary tool to investigate landslide Vulnerability in some tin mine sites of Jos south Plateau State, North-Central Nigeria. The specific objectives of the research include to

1. Carry out 2-D Electrical Resistivity

2. Identify water bearing zone

3. Interpret the result. 


\subsection{Materials}

\section{Materials And Method}

The materials and equipment used for the field work include: ABEM Terrameter SAS 4000 with a $12 \mathrm{~V}$ external power source; A DELL Inspiron E1505 laptop computer; Lund CVES cable in four sections (330019 25/26), including cable joints; stainless steel electrodes; Garmin Global Positioning System; Geological hammer; Silva compass with clinometer; 2 (500m) Measuring Tape.

\subsection{Method}

The configuration used here was the Wenner-Schlumberger method. The Wenner-Schlumberger array is a reasonable all-round configuration to use if both good horizontal and vertical resolutions are needed. The apparent resistivity (observed data) was then iteratively subjected to inversion process using RES2DINV software, to generate the 2-D resistivity sections. The data was inverted with the standard least squares smoothness-constraint. The forward resistivity calculation was executed by applying an iterative algorithm based on finite difference method. The inversion program divided the subsurface into a number of small rectangular prisms and attempted to determine the resistivity values of the model prisms directed towards minimizing the percentage difference between the logarithms of calculated and the observed apparent resistivity values. The quality of the fit is expressed in terms of the Root Mean Square (RMS) error.

\section{Results And Analysis}

The 2-D resistivity models are shown in Figs. 2-17. It is important to note here that survey was carried at the peak of the dry season (January). Vom 1 resistivity section registered the lowest resistivity range of $18.42 \Omega \mathrm{m}-88.62 \Omega \mathrm{m}$ while Rakparak Shen resistivity section registered the highest resistivity range of $35.90 \Omega \mathrm{m}-11,352 \Omega \mathrm{m}$. Probable igneous intrusions and fractures were observed within the subsurface at the following profiles: Kwang Rayfield 1 and 2 (Figs. 2 and 3), Doi 1 and 2 (Figs. 4 and 5), Rapkparak Shen (Fig. 6) and Kwata Zawan 1 and 2 (Figs. 12 and 13). This suggests a possible relationship between these fractures and igneous intrusions. The fractures within the subsurface could have resulted as magma intruded by injection into the initial fractures of the basement rock during formation of the igneous intrusions and can act as host or passage to minerals and fluids. The probable igneous intrusions in the area could be dykes and/or granite plutons. Dykes and granite plutons cause prominent high resistivity zones compared to the surrounding rocks because of their hard nature. In this study, they appear as high resistive bodies.

Figs. 7, 8, 10, 11, 14, 15, 16 and 17 show 2-D resistivity models that generally increase with depth. This implies increase in solidification, compaction and compression with depth. These areas are probably free and safe from landslides to some extent since resistivity largely increases with depth and the low resistivity zone overlies the high resistivity zone. The 2-D resistivity model for Gyerro 1 (Fig. 8) revealed low resistivity values along this profile up to an average depth of about $15 \mathrm{~m}$. This could be due to the nature of the overburden and weathered basement, which consists of high content of clayey material, Cassiterite bearing alluvium and water. At the time of the survey there was active informal mining activity taking place in the area. Figs. 14 and 15 (Vom 1 and 2) show very low resistivity values probably because of the waterlogged nature of the location as there was still evidence of location being flooded during the rainy season, the presence of clay and varying decomposition of basalt. Vom 1 and 2 have very thick overburden because the average depths to the fresh basement are about $50 \mathrm{~m}$ and $45 \mathrm{~m}$ respectively which represents the depths to the sub basalt valley in these locations. These depths though large are possible because the thickness of basaltic flow according to Macleod et al. (1971) is limited by the depth of the pre-existing valleys and rarely exceeds $61 \mathrm{~m}(200 \mathrm{ft})$ ). Another resistivity profile was taken at Gyerro 2 (Fig. 9) about $1 \mathrm{~km}$ away from the profile at Gyerro 1. The 2-D resistivity model revealed generally very low resistivity values $(4.58 \Omega-176.38 \Omega)$ with the higher values close to the surface (between $40 \mathrm{~m}-190 \mathrm{~m}$ on the surface and up to an average depth of $12 \mathrm{~m}$ ) followed by a general decrease of resistivity with depth and then an increase with depth beyond $64 \mathrm{~m}$. The decrease in resistivity value with depth and general very low resistivity value could be due to a combination of the probable presence of Cassiterite bearing alluvium, clay, infiltration of water from a mine pond (about $200 \mathrm{~m}$ from between $260 \mathrm{~m}$ and $295 \mathrm{~m}$ along the profile), ground water in the weathered basement below this profile. Illegal miners recover tin granules from sand at this pond. The area of very low resistivity from the resistivity model covers more than $3600 \mathrm{~m}^{2}$. Gyerro 1 and 2 area is water logged during the rainy season though this survey was carried out at the peak of the dry season; and active informal mining is still taking place within this area. The probability for the occurrence of a landslide here is high because earth materials (compact, solid and more cemented materials) of high resistivity overlie materials (loose, weaker materials) of low resistivity. This area is a potentially unstable area.

\section{Discussion}

In this study, 2-D Electrical Resistivity Survey has been used as a preliminary tool to detect landslide vulnerability at some tin mine sites in Plateau state. In this study, the method has provided based on the measurement of the electrical resistivity values and their spatial distribution in the subsurface, data in 
identifying high water content areas. The 2-D Electrical Resistivity models revealed resistivity sections with resistivity generally increasing with depth, that is overburden resistivity < granitic weathered basement resistivity < granitic basement. The exception was that of the 2-D resistivity model for Gyerro 2 (Sabongida Kanar 2), which revealed a section with overburden resistivity > granitic weathered < granitic basement resistivity. The fluid flow mechanism and weathered zone as indicated by the low resistivity values show the presence of a weak zone within the subsurface of Gyerro 2 where landslides can form. During heavy rainfall, top soils (Lateritic) of this area will be highly saturated with water, thus increasing the weight of the soil. As the moisture content increases, simultaneous weight of overburden material also increases. This increases the stress on the weathered zone (weak zone). Further increase in hydrostatic pressure can induces the slide and a landslide can occur. This mechanical process and the slope of the ground surface are important factors for sliding. Hence, the subsurface of Gyerro 2 area is likely unstable with an area of very low resistivity (4.58 $\Omega$ $36.4 \Omega$ ) of greater than $3600 \mathrm{~m}^{2}$. This may also be the area within the subsurface of Gyerro 2 with high content of clayey material, Cassiterite bearing alluvium and water between the slide material and bedrock. In terms of the direct correlation between electrical resistivity and soil water content, [12 and 13] established relationships between apparent electrical and water content. The regression analyses obtained in the [12 and 13] studies were $0.88-0.94$ and $0.53-0.60$, respectively. These suggest moderate to strong correlation. Given, therefore, that there is a correlation between electrical resistivity and water content, there is the potential for the use of electrical resistivity profiling to estimate the location of a failure surface. Also, the area is prone to flooding because it is waterlogged during the rainy season and the presence of a mine pond. As a result, the area prone to land sliding. Land sliding and flooding are closely allied because both are related to precipitation, runoff, and the saturation of ground by water [1]. From the results also, Gyerro 1 is more stable than Gyerro 2, but over time as informal mining activities continue to take place and the area with its peculiar overburden structure continues to get water logged during the rainy season, the probability of Sabon Gida Kanar 1 area becoming unstable and landslide vulnerable is high.

\section{Conclusion}

According to [7], slope failure (sliding) of the overburden only occur at the Sabon gida kanar mine. This occurs mostly in the raining season, suggesting that water contributes and/or facilitate the sliding [7]. Water probably makes the clay soft and slippery. This study has shown very low 2-D resistivity values for the subsurface of two profile taken at this mine. The study has also shown 2-D resistivity models of other mines in Jos south Plateau state, with an increase of resistivity with depth. This implies increase in solidification, compaction and compression with depth in the subsurface of other mines. Implying that these mines are probably free and safe from landslides to some extent since resistivity largely increases with depth and the low resistivity zone (overburden) overlies the high resistivity zone (weathered basement). This agrees with [7], that mentioned that slope failure (sliding) of overburden do not occur at other mines. It can be concluded that the nature of the overburden at Sabon Gida Kanar mine makes it vulnerable to landslides though active open cast mining using draglines no longer occur but reworking of the overburden and lotto mining takes place in this area almost on daily basis.

This study is just a preliminary study and since landslides are complex phenomena whose study necessarily requires a multidisciplinary approach based on a wide range of observations including geological and geomorphological mapping, geotechnical and geophysical investigations (Seismic Refraction), geodetic surveys, satellite observations and meteorological data analysis. It is recommended that various experts in the above mentioned areas carry out researches to get data from the Gyero (Sabon Gida Kanar) tin mine in particular and other tin mines in Plateau state in general.

\section{References}

[1] L. Highland, Landslide types and processes, U.S.Geological Survey Facts Sheet 2004-3072. http://pubs.usgs.gov/fs/2004/3072/

[2] J.I. Igbokwe, J.O. Akinyede, B. Dang, T. Alaga, M.O. Ono, V.C. Nnodu et al., Mapping and monitoring of the impact of Gully Erosion in South-eastern Nigeria with satellite Remote Sensing and Geographic Information System. International Archives of Photogrammetry, Remote Sensing and Spatial Information Sciences. 37 (B8), 2008, 865-871.

[3] T.O. Ako, F.M. Abba, U.S. Onoduku, W.M. Nuhu, et al., The October 13, 2010 Landslides on the Azenge Mountainin Imande Ukusu, Nkomon Disrict, Benue State, Nigeria. Environment and Ecology Research. 2(3), 2014, 113-121. DOI: 10.13189/eer.2014.020301. http://www.hrpub.org.

[4] C. O. Okagbue, Stability analysis of a slip-debris flow in the Ogbajalala Hills of Benue State, Nigeria, Natural hazards, 2(2), 2003,143-153, DOI: 10.1007/BF00141244.

[5] J.A. Olaniyan, Project of overview and socio - economic impact of tin mining. Land Consultant. State Secretariat Cabinet Office Jos, 9-6, 1998, 43-49.

[6] T. Balogun, The Changing Landscape of Jos, Nigeria. Escape From America Magazine 9(11) Nov/Dec 2007. http://www.escapeartist.com/efam/97/changing_landscape_of_Jos.html

[7] F.O. Ugodulunwa, and T.A. Omolaja, Guide on Excursion to Tin and Kaolin Exploitation site near Jos. (The Nigerian Mining and Geosciences Society, 1994)12

[8] J. M. Reynolds, An Introduction to Applied and Environmental Geophysics (John Wiley and Sons, New York , 1997$) 796$. 


\section{2-D Electrical Resistivity Imaging for Detecting Landslide Vulnerability of Some Tin Mine Sites in}

[9] D. Jongmans and S. Garambois, Geophysical investigation of landslide: A review. Bulletin of the Geological Society of France, 178 (2), 2007, 101-112. DOI: 10.2113/gssgfbull.178.2.101

[10] V. Lapenna, P. Lorenzo, A. Perrone, S. Piscitelli, E. Rizzo and F. Sdao, 2-D Electrical resistivity imaging of some complex landslides in Lucanian Apennine (Southern Italy). Geophysics, 70, (3), 2005 B11-B18.

[11] A. Godio, C. Strobbia, and G. DE Bacco, Geophysical characterisation of a rockslide in an alpine region. Engineering Geology, 83, 2006, 86-273.

[12] R.G. Kachanoski, E.G. Gregorich, and I.J. Van Wesenbeeck, Estimating spatial Variations of soil water content using noncontacting electromagnetic inductive methods, Canadian Journal of Soil Science, 68, 1988, 715-722.

[13] P.J. Vaughn, S.M. Lesch, D.L. Corwin and D. G. Cone, Water content effect on Soil Salinity prediction:a geostatistical study using Cokriking, Soil Science Society of America Journal, 59,1995,1146-1156.
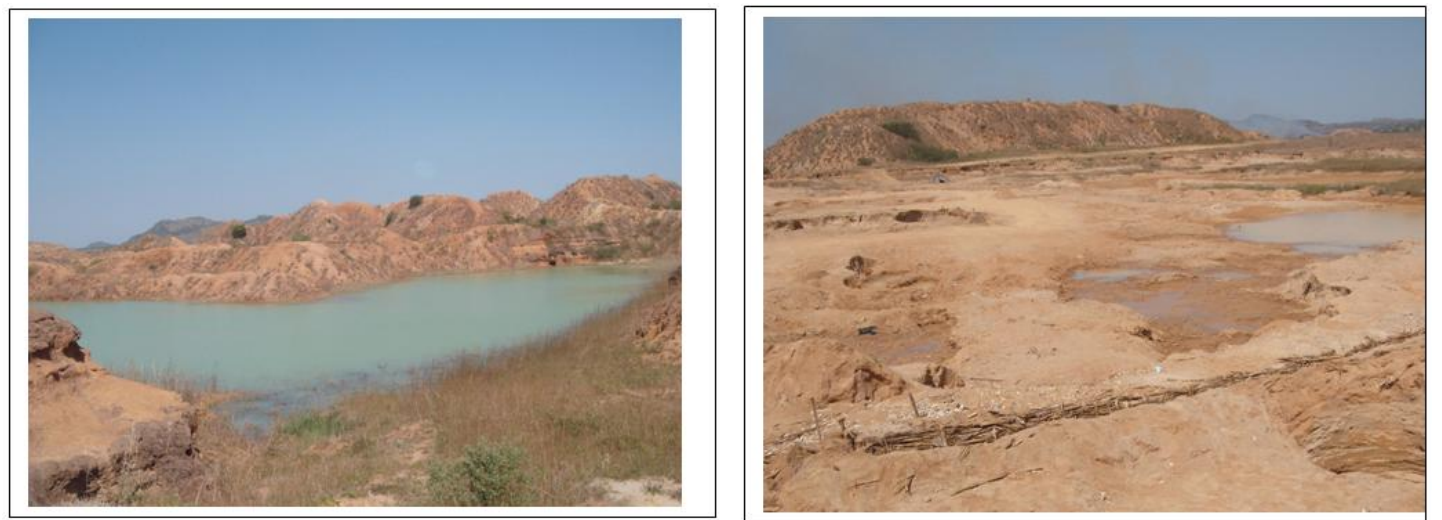

Plate 1: Mine pond and dumped high overburden at (a) Kwang Rayfield (b) Gyerro (Sabon Gida Kanar) JosSouth, Plateau State, Nigeria

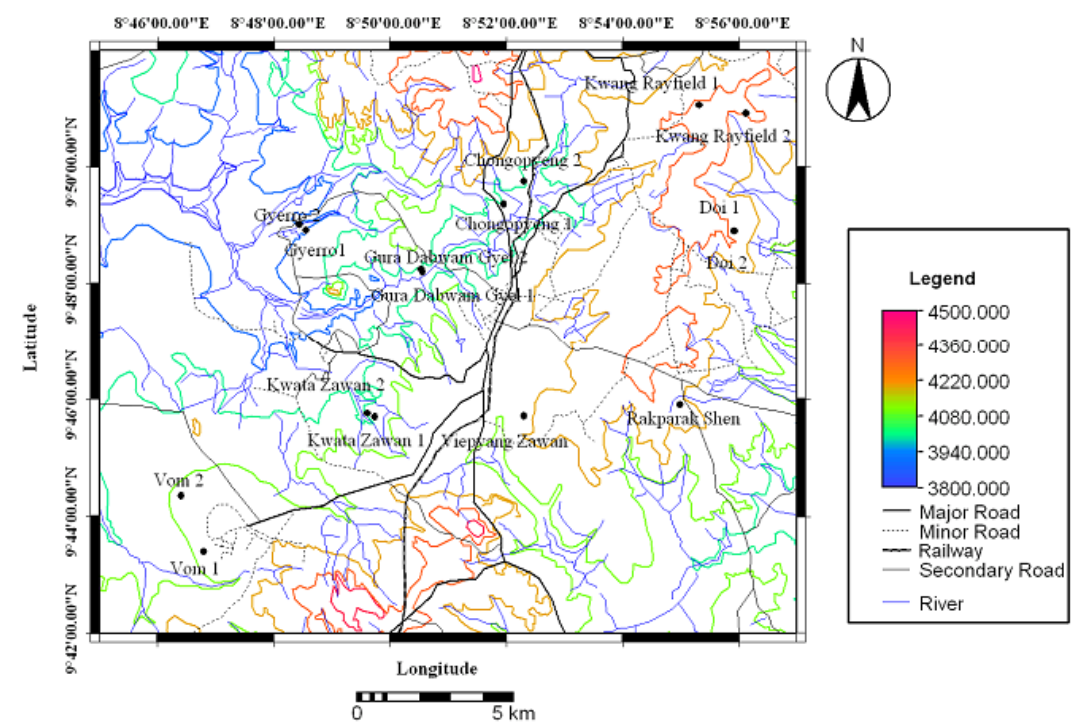

Fig. 1: Topography map showing locations covered during the fieldwork (Extracted from Topography Map of Naraguta Sheet 168, Published by Federal Surveys of Nigeria, 1962). Elevation contours in metres.

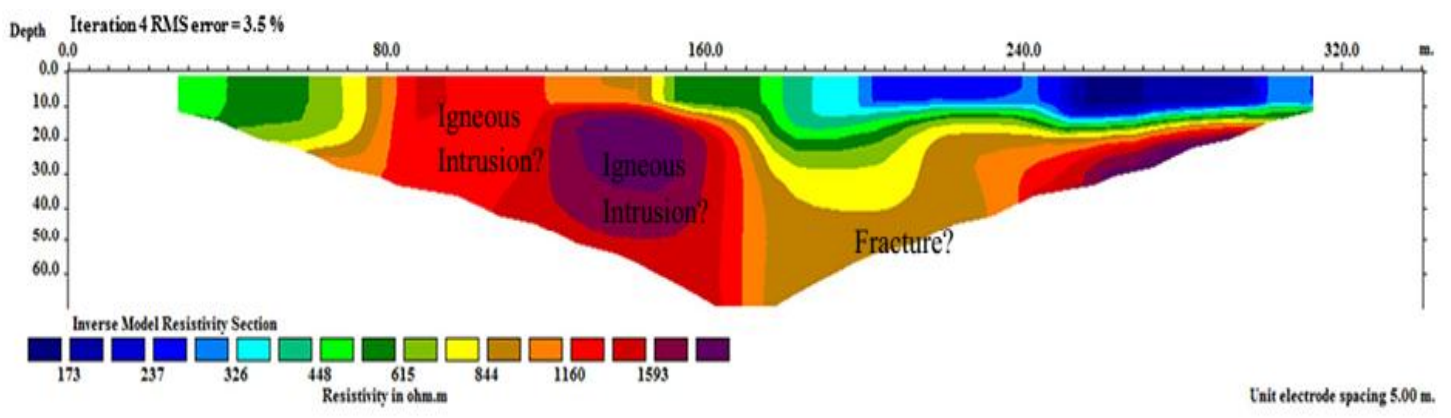

Fig 2: 2-D Resistivity Model of Kwang Rayfield 1 (depth in metres). 


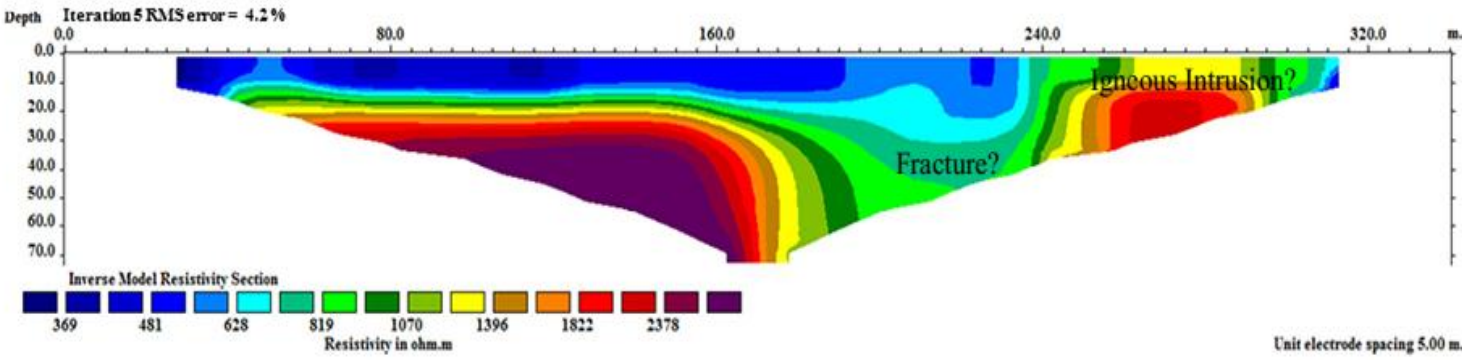

Fig. 3: 2-D Resistivity Model of Kwang Rayfield 2 (depth in metres).

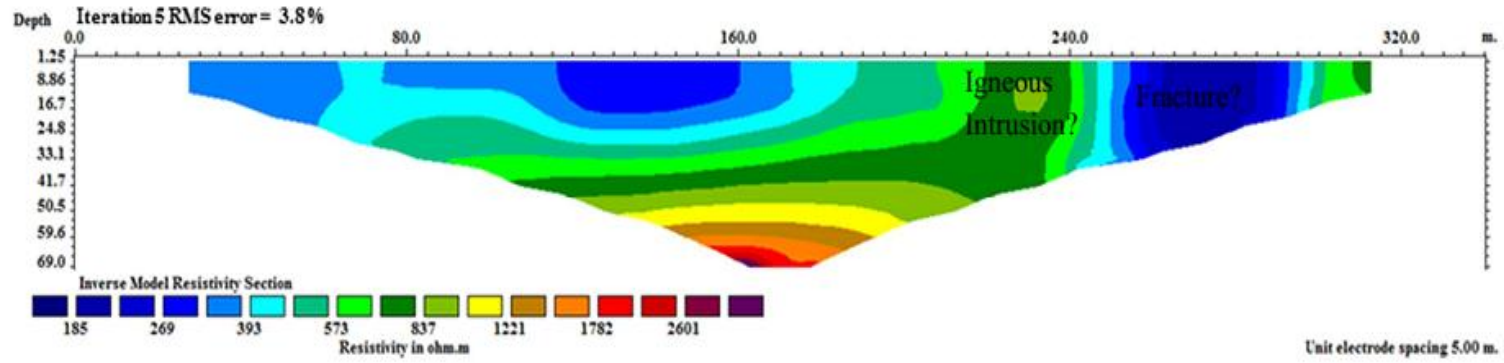

Fig. 4: 2-D Resistivity Model of Doi 1 (depth in metres).

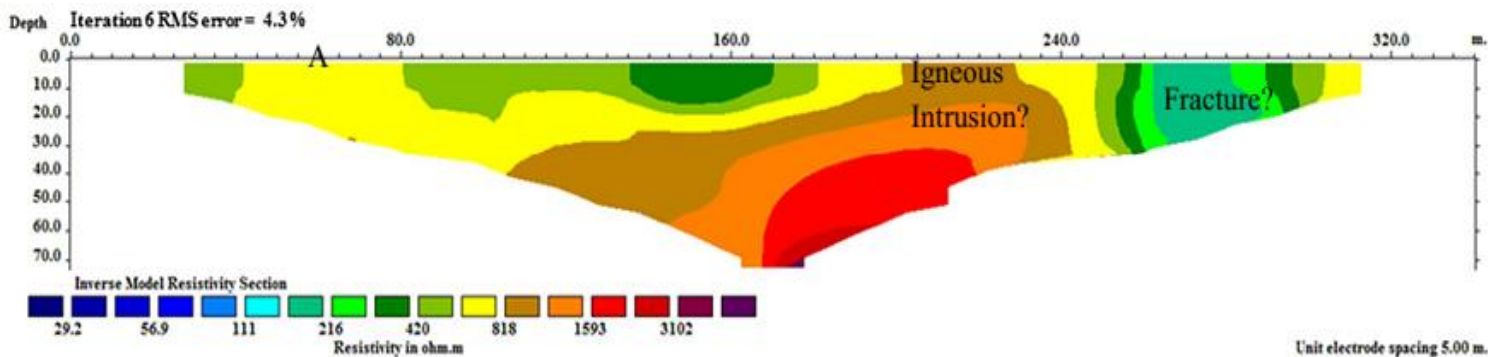

Fig.5: 2-D Resistivity Model of Doi 2 (depth in metres).

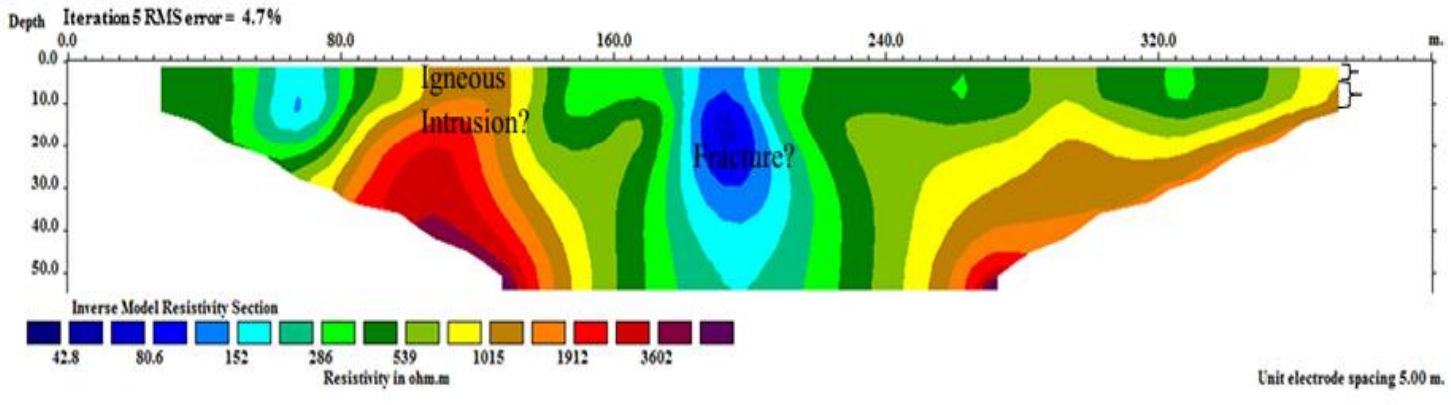

Fig. 6: 2-D Resistivity Model of Rakparak Shen (depth in metres).

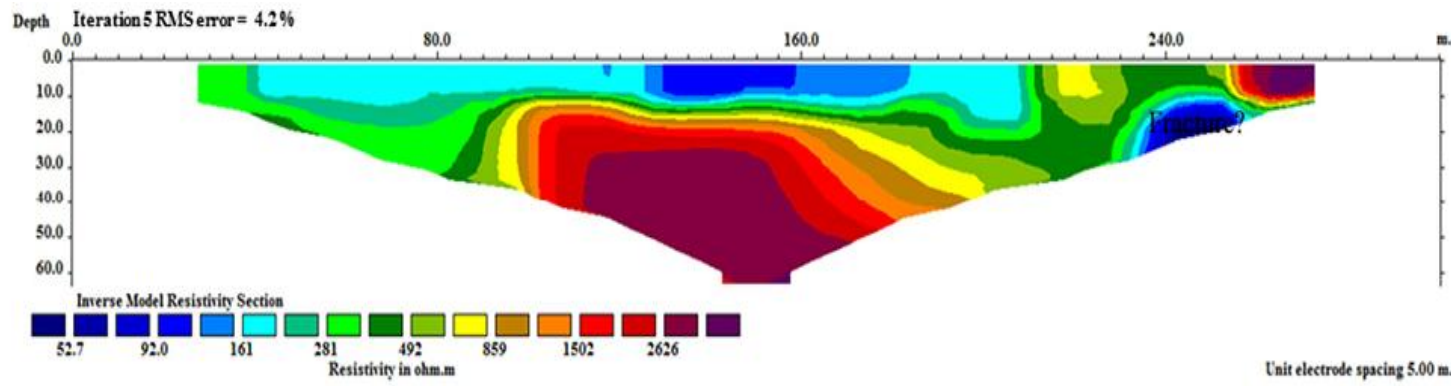

Fig. 7: 2-D Resistivity Model of Viepyang Zawan (depth in metres). 


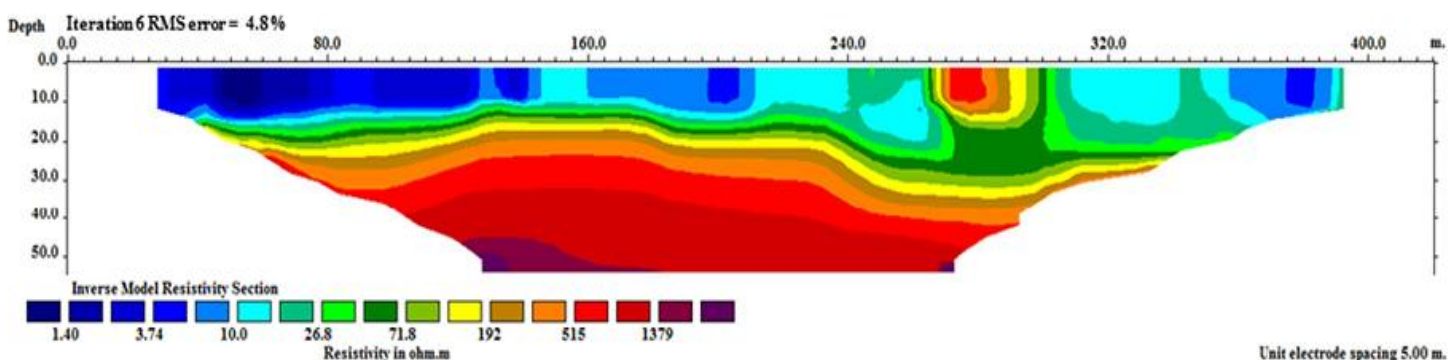

Fig. 8: 2-D Resistivity Model of Gyerro (Sabon Gida Kanar) 1 (depth in metres).

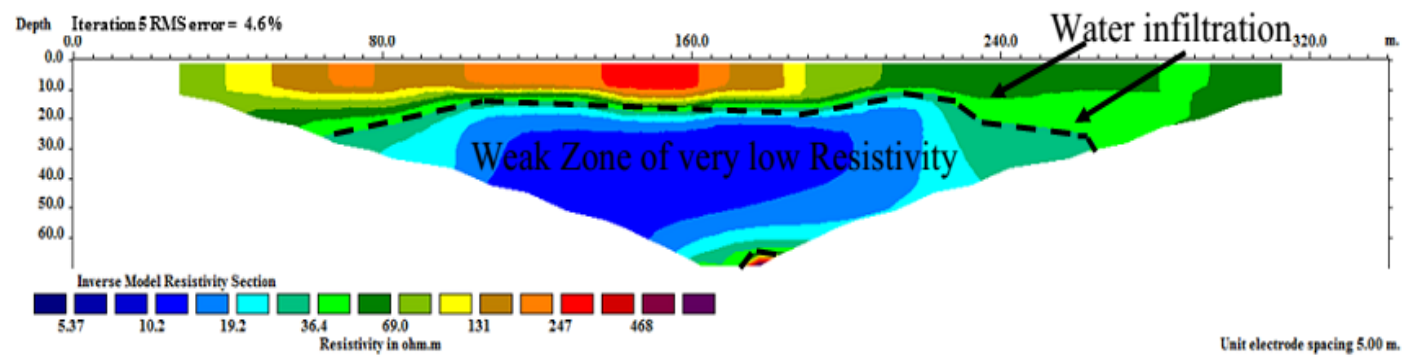

Fig. 9: 2-D Resistivity Model of Gyerro (Sabon Gida Kanar) 2 (depth in metres).

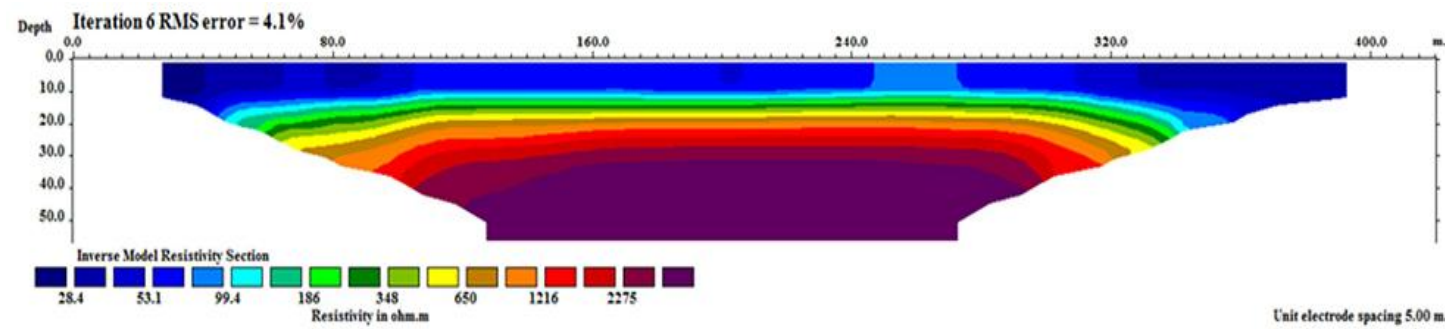

Fig.10: 2-D Resistivity Model of Gura Dabwam Gyel 1 (depth in metres).

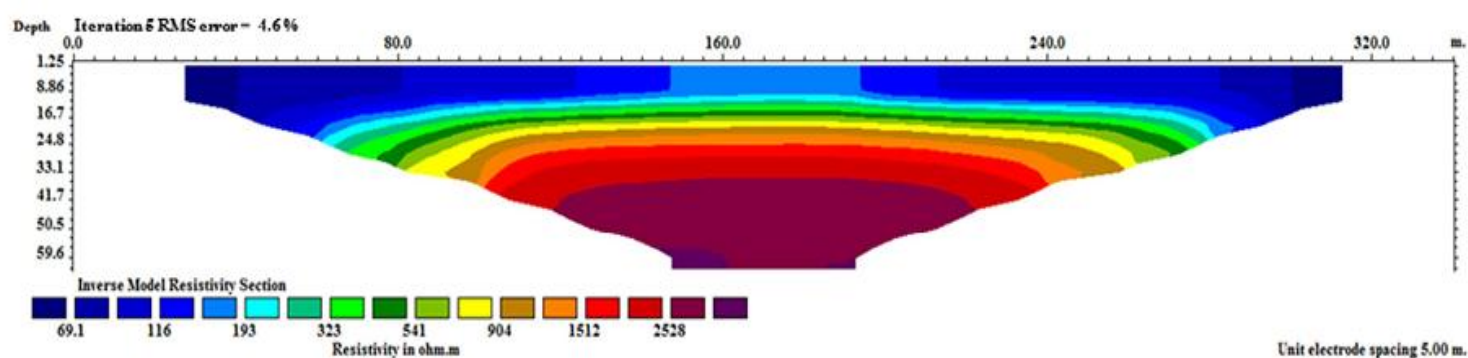

Fig. 11: 2-D Resistivity Model of Gura Dabwam Gyel 2 (depth in metres).

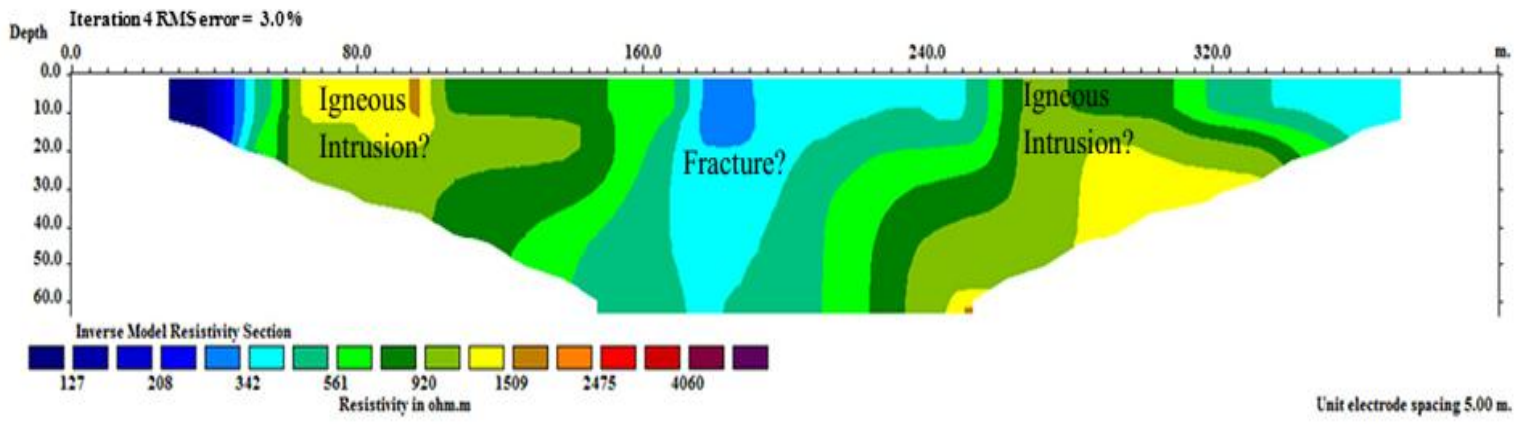

Fig. 12: 2-D Resistivity Model of Kwata Zawan 1 (depth in metres). 


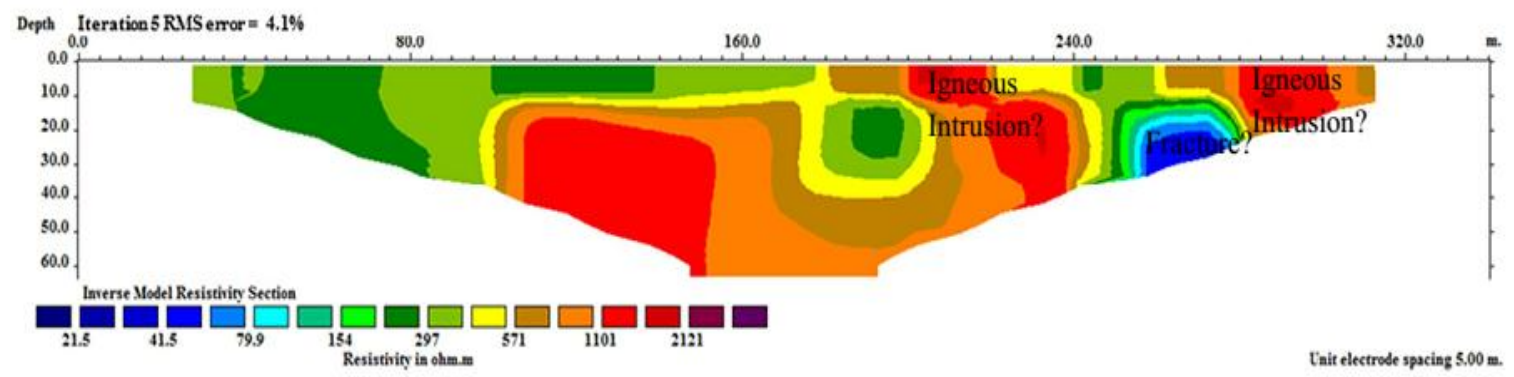

Fig. 13: 2-D Resistivity Model of Kwata Zawan 2 (depth in metres).

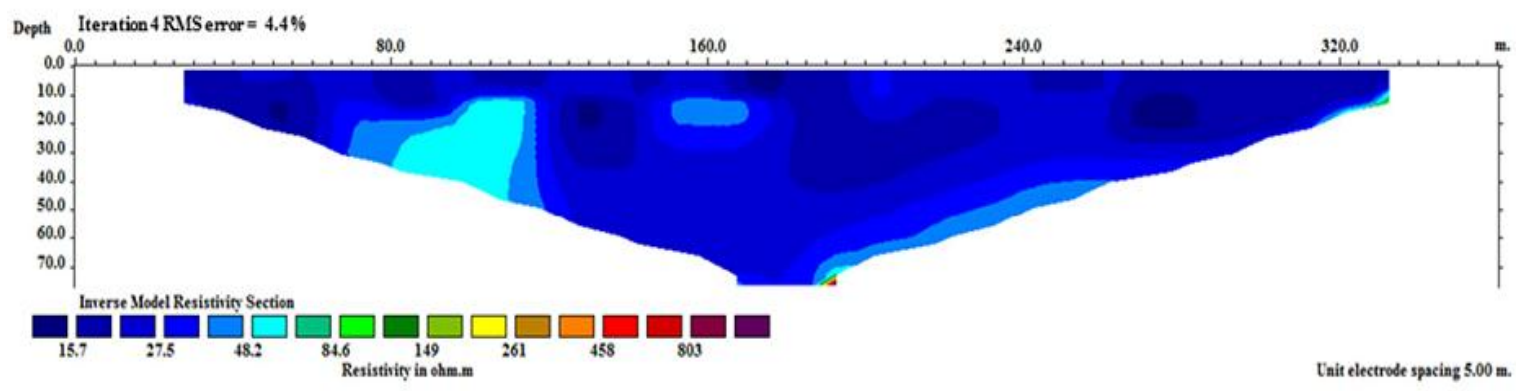

Fig. 14: 2-D Resistivity Model of Vom 1 (depth in metres).

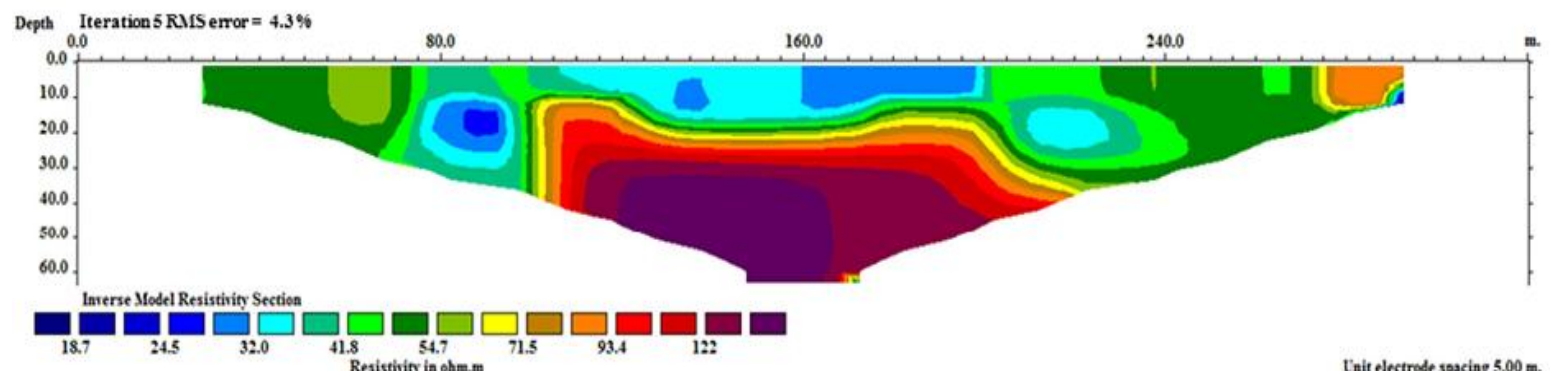

Fig.15: 2-D Resistivity Model of Vom 2 (depth in metres).

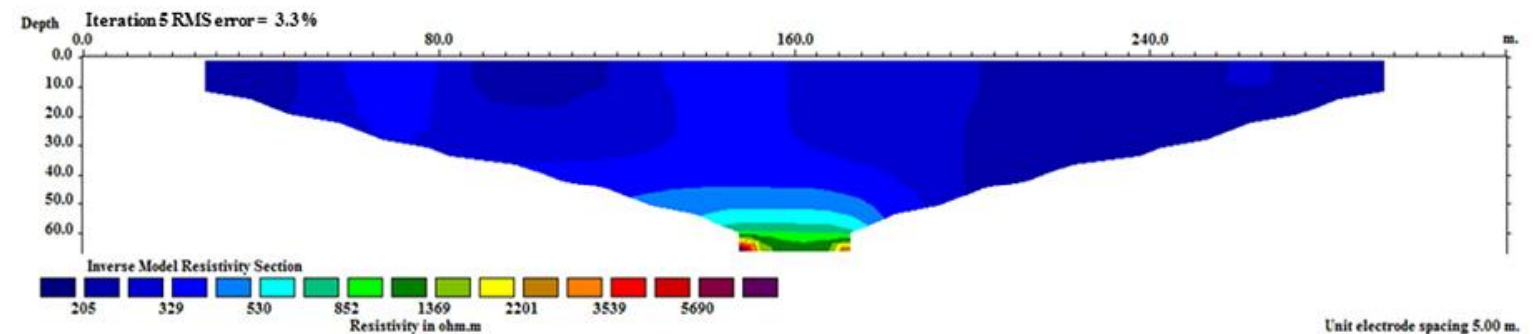

Fig. 16: 2-D Resistivity Model of Chongopyeng 1 (depth in metres).

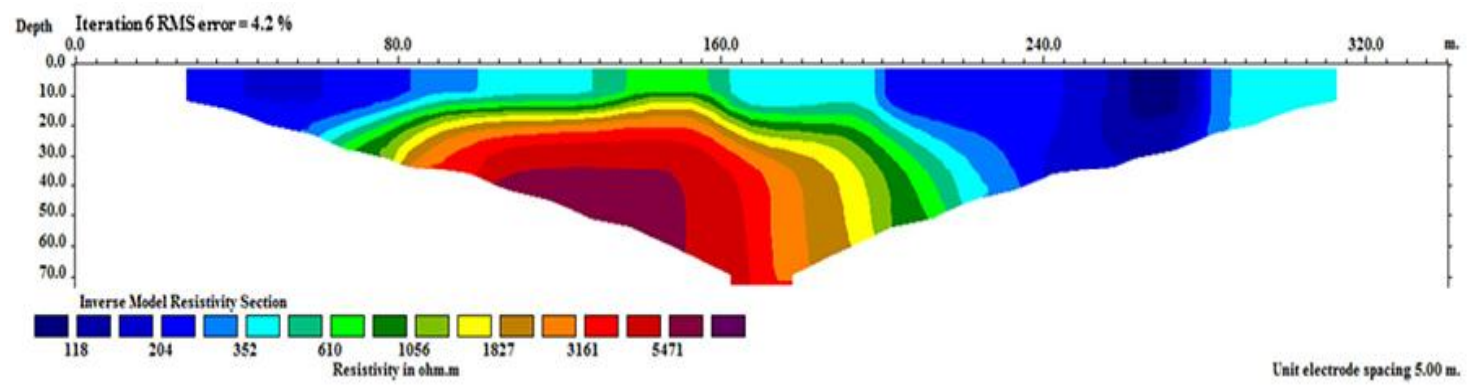

Fig. 17: 2-D Resistivity Model of Chongopyeng 2 (depth in metres). 